\title{
Extremes of Temperature, Oxygen and Blooms in the Baltic Sea in a Changing Climate
}

\author{
Thomas Neumann, Kari Eilola, Bo Gustafsson, Bärbel Müller-Karulis, \\ Ivan Kuznetsov, H. E. Markus Meier, Oleg P. Savchuk
}

\begin{abstract}
In the future, the Baltic Sea ecosystem will be impacted both by climate change and by riverine and atmospheric nutrient inputs. Multi-model ensemble simulations comprising one IPCC scenario (A1B), two global climate models, two regional climate models, and three Baltic Sea ecosystem models were performed to elucidate the combined effect of climate change and changes in nutrient inputs. This study focuses on the occurrence of extreme events in the projected future climate. Results suggest that the number of days favoring cyanobacteria blooms could increase, anoxic events may become more frequent and last longer, and salinity may tend to decrease. Nutrient load reductions following the Baltic Sea Action Plan can reduce the deterioration of oxygen conditions.
\end{abstract}

Keywords Baltic Sea - Climate change - Modeling . Ecosystem

\section{INTRODUCTION}

During the last century, intensive land use, the application of fertilizers, and waste water discharge from urban settlements in combination with restricted water exchange with the North Sea has resulted in a eutrophied Baltic Sea. Increasing phytoplankton biomass, decreased water transparency, stronger and more frequent cyanobacteria blooms, and less oxygen in the bottom water are the responses of the ecosystem to eutrophication (Elmgren 2001; Finni et al. 2001). In particular, cyanobacteria cause environmental concern due to their potential toxicity and their ability to

Electronic supplementary material The online version of this article (doi:10.1007/s13280-012-0321-2) contains supplementary material, which is available to authorized users. fix dinitrogen, which may contribute up to $50 \%$ of the total nitrogen loads to the Baltic Sea (Wasmund et al. 2005). Cyanobacteria blooms usually start in summer under the conditions of water temperatures higher than $16-17^{\circ} \mathrm{C}$, along with calm weather and high irradiation (Wasmund 1997).

Salinity in the Baltic Sea is controlled by the freshwater budget and by the water exchange with the North Sea. The estuarine circulation of the Baltic Sea results in a strong density stratification that hampers the vertical exchange between surface and bottom water. Owing to this stratification, hypoxic and anoxic conditions occur in the bottom water. The varying oxygen conditions and the brackish water in the Baltic Sea require organisms to adapt to these changing conditions, and they often live at their physiological limits (e.g., Feistel et al. 2008). Extreme events may under these circumstances be an important driver for ecosystem structure (Walther et al. 2002). Temperature events can trigger ecosystem shifts if a critical thermal boundary is passed (Jiguet et al. 2011), and hypoxic events may cause mass mortality, especially of benthic communities (Diaz and Rosenberg 2008). For many species, low oxygen concentrations alone must not be crucial as they are adapted to such conditions and are able to survive for a certain time; then the duration of such a low-oxygen event becomes an important factor for survival. Moreover, the drastic change in redox conditions alters the biogeochemical fluxes. The likely most crucial effect is the liberation of iron-bound phosphate from the sediment. This is considered a self-eutrophication process (Vahtera et al. 2007).

For the future, climate change projections for the Baltic Sea suggest warmer sea water, a tendency towards lower salinity, and less sea ice in the future (BACC 2008), with considerable impacts on the marine ecosystem, such as increased phytoplankton concentrations (Meier et al. 
2011a) and extended hypoxic areas (Meier et al. 2011c). One objective of the Baltic Sea Action Plan (BSAP; HELCOM 2011) is the improvement of the oxygen conditions in the Baltic Sea deep water to be achieved by a reduction of riverine nutrient loads. A crucial question is whether the BSAP measures have the same desired effect under the conditions of a warmer climate as under today's climate. Here, we will assess and discuss how extreme values of temperature, oxygen, and cyanobacteria blooms, which are important drivers and indicators for the state of the Baltic Sea ecosystem, could change in a future climate.

\section{MATERIALS AND METHODS}

A multi-model ensemble simulation has been performed to assess the Baltic Sea ecosystem status in a future climate (Meier et al. 2011c). Each of these experiments in the ensemble is subject to a specific evolution in time, depending on the future climate projection (IPCC scenario) and the models that are used. With an ensemble it is possible to estimate uncertainties originating from the unknown future climate and socio-economic development as well as insufficient representation of physical and biogeochemical processes in the models.

For this study, we use a subset of the model experiments described in Meier et al. (2011c) based on the IPCC A1B (IPCC 2007, 2009) greenhouse gas emission scenario. The IPCC scenario was realized by the global circulation models ECHAM5 (Roeckner et al. 2006) and HadCM3 (Gordon et al. 2000). From the ECHAM5 simulation, three realizations were used. The selection of GCMs is motivated by their performance for the Baltic Sea region (Meier et al. 2011b). The global scenarios were downscaled by two regional climate models (RCMs): the CLM (CLM Community 2011) and the RCAO (Döscher et al. 2002). RCAO is a coupled atmosphere ocean model, while the CLM is an atmospheric model only with prescribed boundary conditions at the sea surface from the global model. The performance of the CLM and RCAO downscaling simulations were analyzed by Hollweg et al. (2008) and Meier et al. (2011b), respectively. Both studies concluded that the control period was satisfactorily represented by the models.

The output of the downscaled climate model experiments was used as meteorological forcing for three Baltic Sea ecosystem models. These are the Ecological ReGional Ocean Model (ERGOM, Neumann and Schernewski 2008), the Swedish Coastal and Ocean BIogeochemical model coupled to the Rossby Center Ocean circulation model (RCO-SCOBI, Eilola et al. 2009), and the BAltic sea LongTerm large Scale Eutrophication Model (BALTSEM, Savchuk 2002). ERGOM and RCO-SCOBI are explicit 3D models while BALTSEM resolves the Baltic Sea in 13 dynamically interconnected and horizontally integrated sub-basins with high vertical resolution.

The involved Baltic Sea ecosystem models each consist of a hydrodynamic and a biogeochemical part. The biogeochemical formulations have the following common features: All three biogeochemical models describe the coupled cycles of nitrogen and phosphorus. Organic matter is produced from dissolved inorganic nutrients by three functional phytoplankton groups: large cells, small cells, and cyanobacteria. Secondary production is simulated by a bulk zooplankton. Dead particles sink down and are accumulated in a sediment pool. Mineralization of dead organic matter into dissolved nutrients occurs in the water and in the sediment pool. Oxygen dynamics is coupled to the biogeochemical processes and hydrogen sulfide is represented by negative oxygen equivalents. The biogeochemical models differ in their representation of the nitrogen to phosphorous ratio in dead organic matter, the parameterization of sediment phosphorous dynamics, and the description of resuspension and sediment transport. A detailed description of the models and their performance can be found in Eilola et al. (2011).

The biogeochemical models were forced with two nutrient load scenarios, a reference scenario (REF) and the BSAP scenario. The REF scenario assumes nutrient loads at today's level while the BSAP scenario implements nutrient loads reductions according to the Baltic Sea Action Plan (HELCOM 2011). All simulations are transient and cover the period of 1960-2100. Altogether, 17 model simulations were used in this study. The available simulations are summarized in Table 1.

Table 1 The multi-model ensemble used in this study

\begin{tabular}{lllll}
\hline GCM & RCM & BSM & REF & BSAP \\
\hline E-r1 & CLM & ERGOM & $\times$ & $\times$ \\
E-r2 & CLM & ERGOM & $\times$ & \\
E-r3 & RCAO & ERGOM & $\times$ & $\times$ \\
H & RCAO & ERGOM & $\times$ & $\times$ \\
E-r3 & RCAO & SCOBI & $\times$ & $\times$ \\
H & RCAO & SCOBI & $\times$ & $\times$ \\
E-r1 & RCAO & BALTSEM & $\times$ & $\times$ \\
E-r3 & RCAO & BALTSEM & $\times$ & $\times$ \\
H & RCAO & BALTSEM & $\times$ & $\times$ \\
\hline
\end{tabular}

Crosses refer to available simulations

GCM Global Circulation Model; $R C M$ Regional Circulation Model; $B S M$ Baltic Sea Model; REF Reference nutrient loads; BSAP Nutrient loads after the Baltic Sea Action Plan; $E$ ECHAM5; $H$ HadCM3; $r 1$, $r 2, r 3$ Realizations 1, 2, 3; CLM CLM RCM; RCAO Rossby Center Atmosphere Ocean Model; ERGOM, SCOBI, BALTSEM Baltic Sea ecosystem models. The GCMs are initially forced by the IPCC greenhouse gas emission scenario A1B 
The multi-model ensemble used in the study may be over-represented by the global model ECHAM5 compared to HadCM3. However, two ECHAM5-based scenarios are also scaled down by the regional CLM model instead of the RCAO model (Table 1), which therefore increases the number of regional models in the ensemble. Meier et al. (2012) found that overall conclusions do not depend on the weighting of particular simulations in this ensemble. Altogether, we consider the ensemble as a reasonable composition of global and regional models for the Baltic Sea region. Nevertheless, it is important to state that the ensemble is not a complete representation of all sources of uncertainty.

This study is focused on the analysis of extreme events and conditions. Therefore, we used model outputs with a high temporal resolution of one day. We confined our analysis to standard HELCOM monitoring stations representing the main characteristics of the respective subbasins of the Baltic Sea. The locations shown in Fig. 1 are in the deep parts of the sub-basins and are regularly sampled by the Baltic Sea monitoring program. Data from the 3D ecosystem models represent the stations while data from the basin scale model BALTSEM provide horizontally integrated values representative for the considered basin.

In a first step, we identified events with extreme conditions, e.g., by exceeding a certain threshold value. For these events we estimated the occurrence probability. This probability describes the risk that at any day in the year (or season) an event occurs. To estimate the statistical properties of the occurrence probabilities, we applied the bootstrap method and calculated the ensemble mean and the non-parametric $95 \%$ spread of the mean. Finally, to

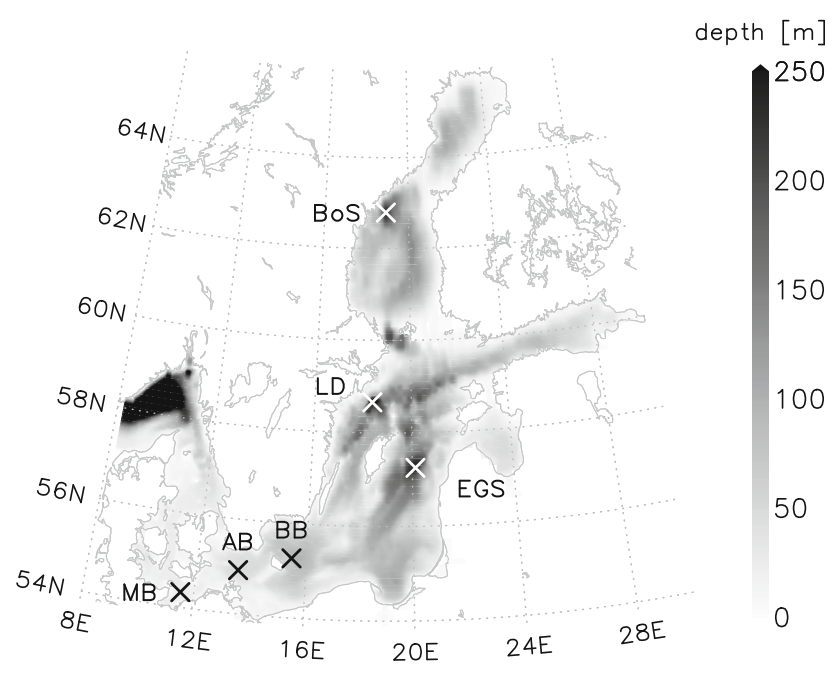

Fig. 1 The model domain. Crosses denote locations of projections. $M B$ Mecklenburg Bight, $A B$ Arkona Basin, $B B$ Bornholm Basin, EGS Eastern Gotland Sea, $L D$ Landsort Deep, BoS Bothnian Sea reduce the variability introduced by weather, the statistical parameters have been filtered with a running mean of 20 years length. For temperature and salinity we used a simple bias correction to harmonize data from different model experiments with the aim that each model time series has the same mean in the control period as the ensemble.

We used the bootstrap method to obtain an estimate of the significance of the trend that is described by the mean value. The change of the projected period is considered significant if the ensemble mean exceeds the $95 \%$ spread (bounds) of the mean in the control period (1970-2000).

\section{RESULTS}

\section{Control Period}

Climate model simulations cannot reproduce the real system on an event basis due to the chaotic behavior of the Earth system. In fact, it is assumed that statistics of climate simulations are representative for the simulated period. In Fig. 2, we provide a brief overview on how the combinations of GCM, RCM, and Baltic Sea models perform in the southern (Bornholm Basin), the central (Eastern Gotland Sea), and the northern (Bothnian Sea) Baltic Sea. This is done by comparing ensemble means with observed mean sea surface temperature (SST) and sea surface salinity (SSS). For an additional evaluation of the control period we refer to Meier et al. (2012).

The ensemble mean SST shows a bias in the order of $1{ }^{\circ} \mathrm{C}$ (Fig. 2) with larger differences in summer which might be due to the warm bias of the RCMs, as discussed in Meier et al. (2011b). The ensemble mean for SSS only shows small deviations from the observations. Together with the quality analysis in Meier et al. (2012), we conclude that the performance of the ensemble simulations in the control period is sufficient for the present analysis.

\section{Future Projections}

In this chapter we present results for future projections of the Baltic Sea ecosystem based on meteorological forcing for climate change scenarios and assumptions for nutrient loads.

\section{Sea Surface Temperature (SST)}

In the Baltic Sea, high SST promote cyanobacteria blooms (Wasmund 1997; Kanoshina et al. 2003; Lips and Lips 2008). Therefore, we have analyzed the occurrence of SST 

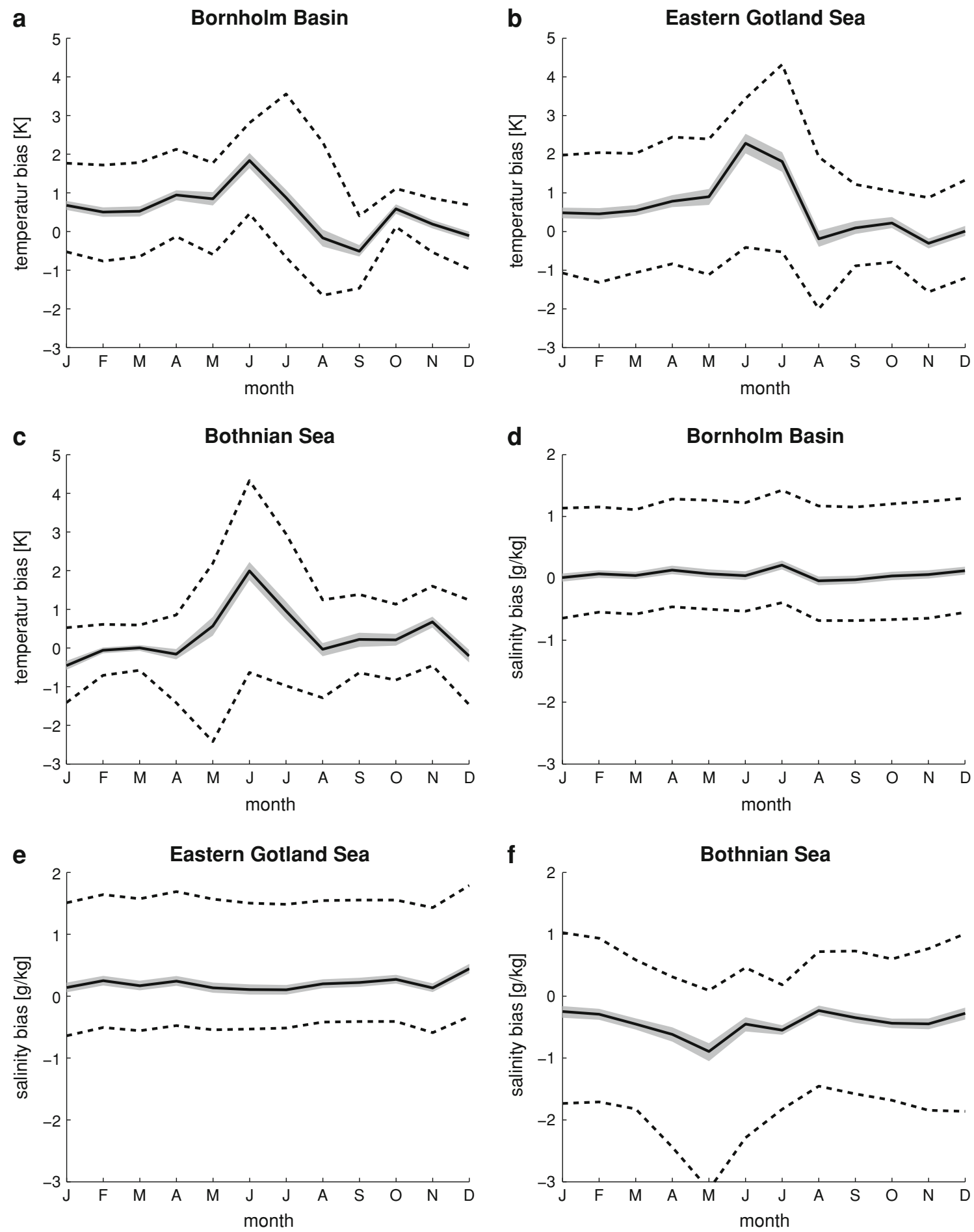

Fig. 2 Sea surface temperature (a-c) and sea surface salinity (d-f) monthly bias of the ensemble mean at different stations in the Baltic Sea for the control period 1970-1999. The solid line is the

ensemble mean and the shaded area shows the $95 \%$ ensemble spread of the mean. The dotted lines are minimum and maximum values in the ensemble. For locations see Fig. 1

exceeding $18{ }^{\circ} \mathrm{C}$ during summer. Figure 3 shows the probability that the daily mean SST is higher than $18^{\circ} \mathrm{C}$ in the summer months June, July, and August. All

investigated basins show a clear trend of increasing probability. Probabilities are highest in the southern part and decrease towards the northern Baltic. In the recent climate, 
a

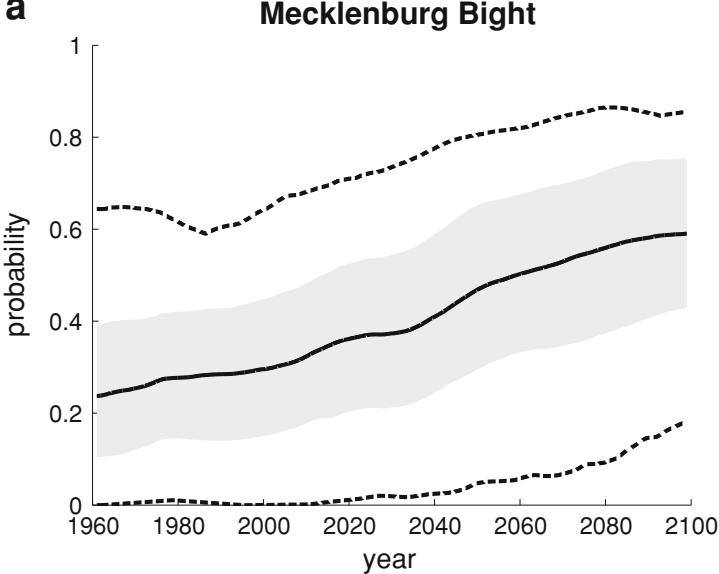

Bornholm Basin

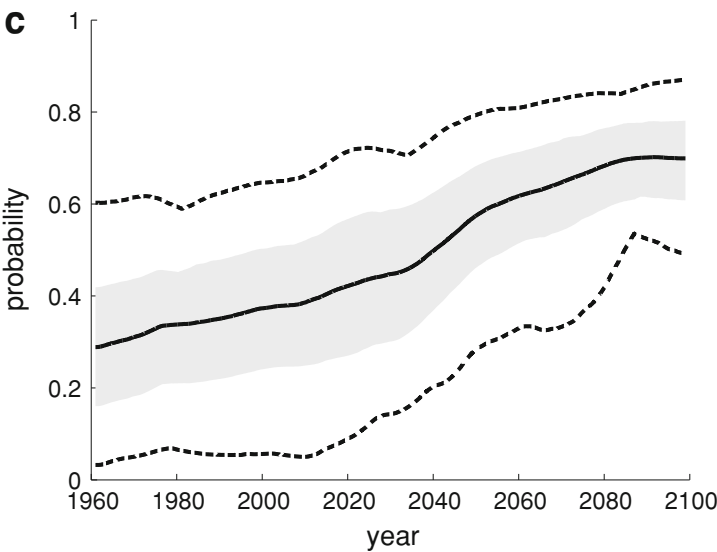

e

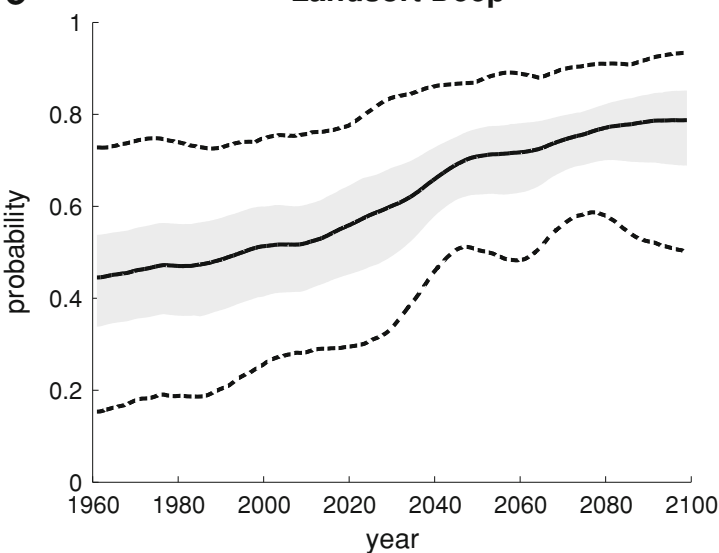

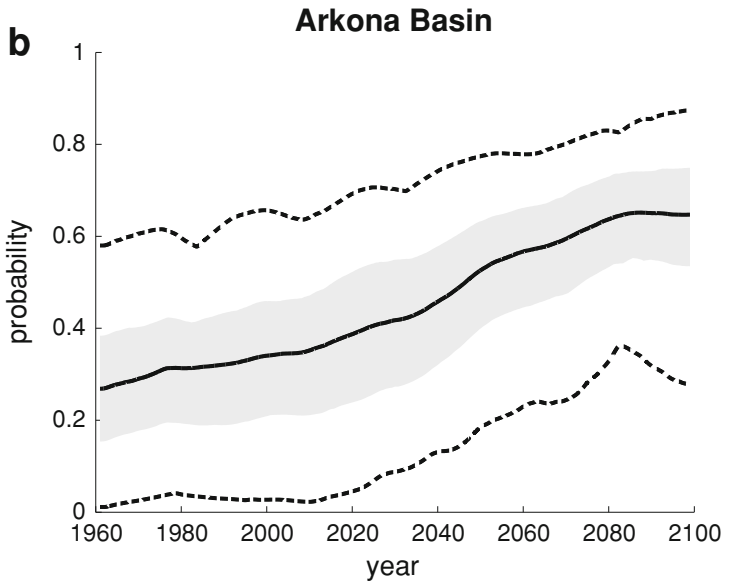

d Eastern Gotland Sea

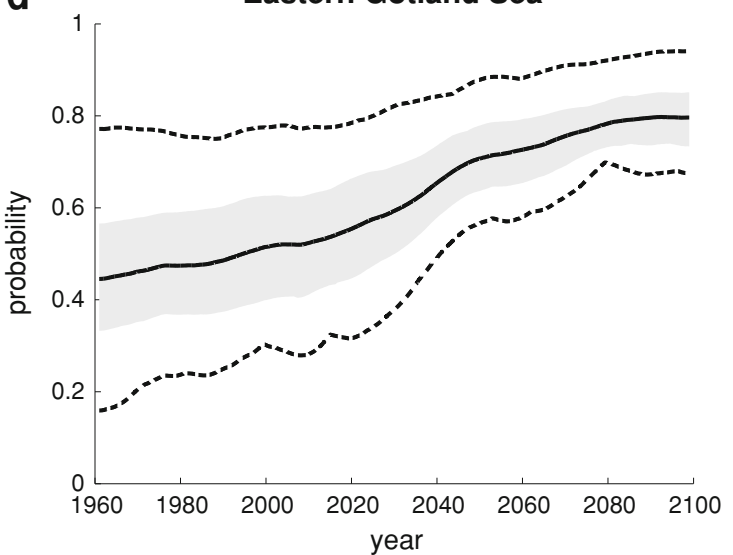

Bothnian Sea

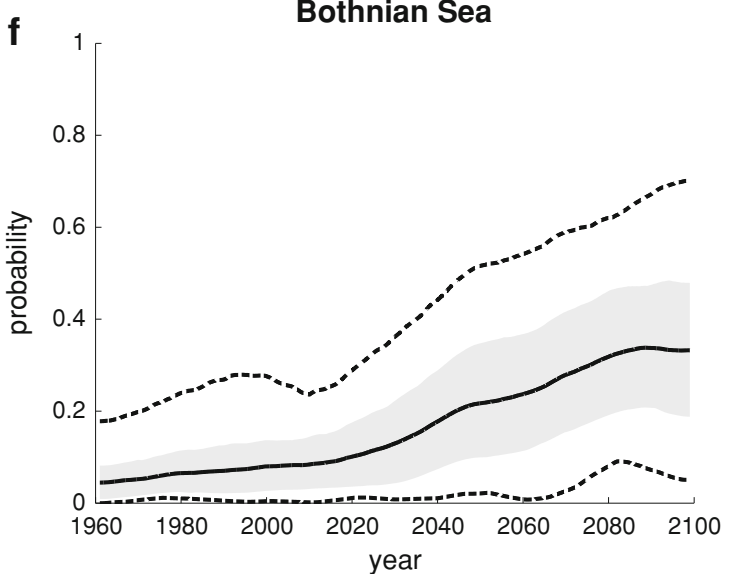

Fig. 3 Probability that SST will exceed $18{ }^{\circ} \mathrm{C}$ in summer (JJA) for different regions. The solid line is the ensemble mean and the shaded area shows the $95 \%$ ensemble spread of the mean. The dotted lines are minimum and maximum values in the ensemble. For locations see Fig. 1

the probability for high SST is in the range up to $30 \%$, while for a future climate at the end of this century the high SST probability reaches values up to $70 \%$. The ensemble spread is small which means that the estimated trends are significant.

\section{Oxygen Conditions}

To evaluate the combined effect of climate and the BSAP reduction efforts on oxygen conditions, we investigated the probability for hypoxic and anoxic conditions. Hypoxic 
a

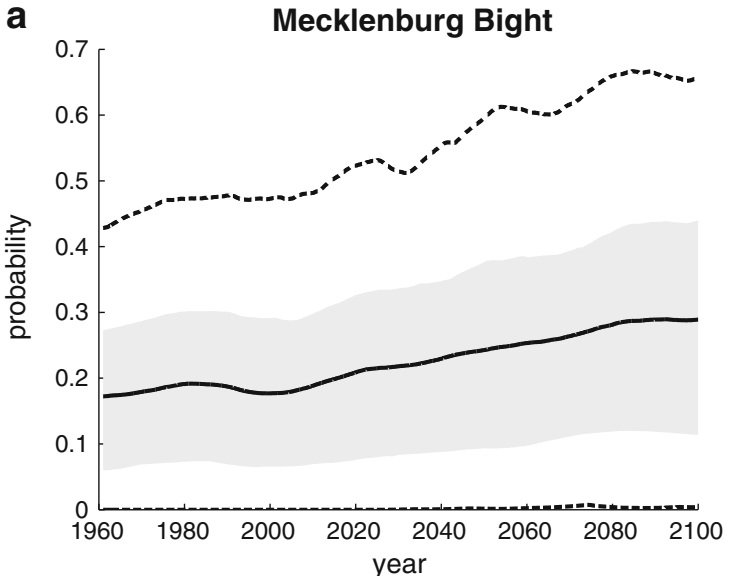

C

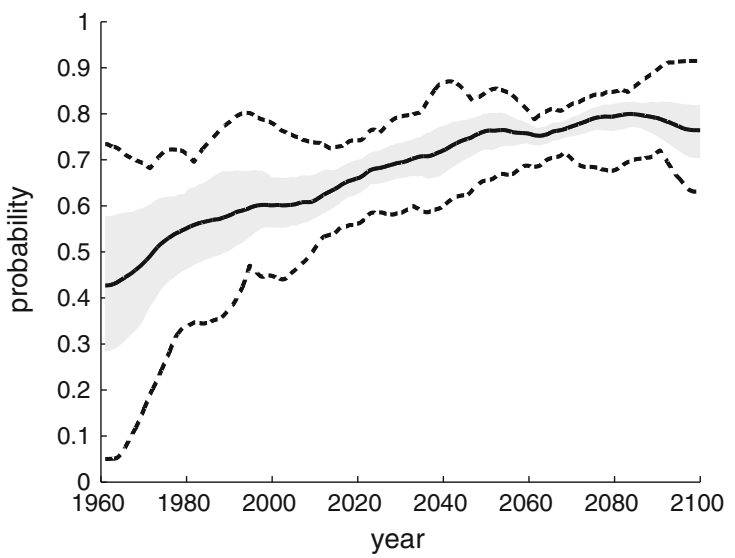

e

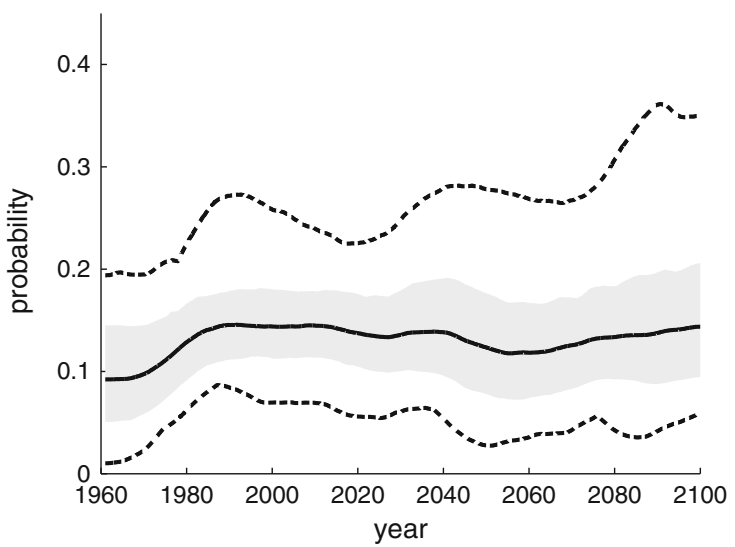

b

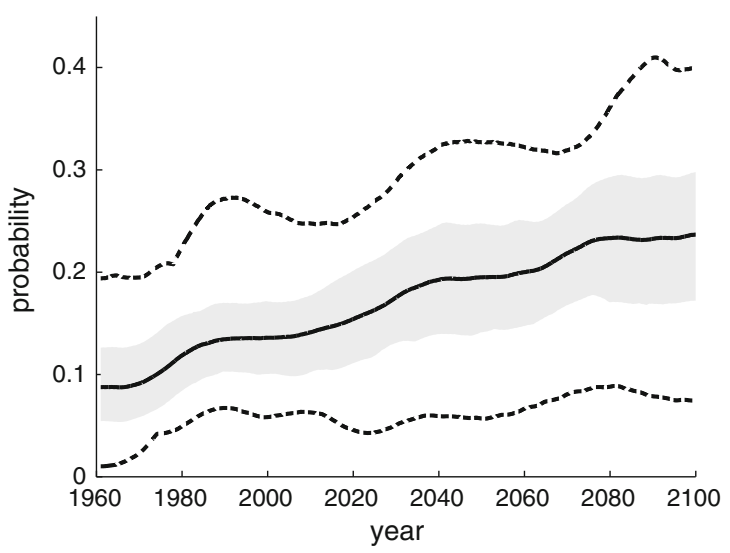

d

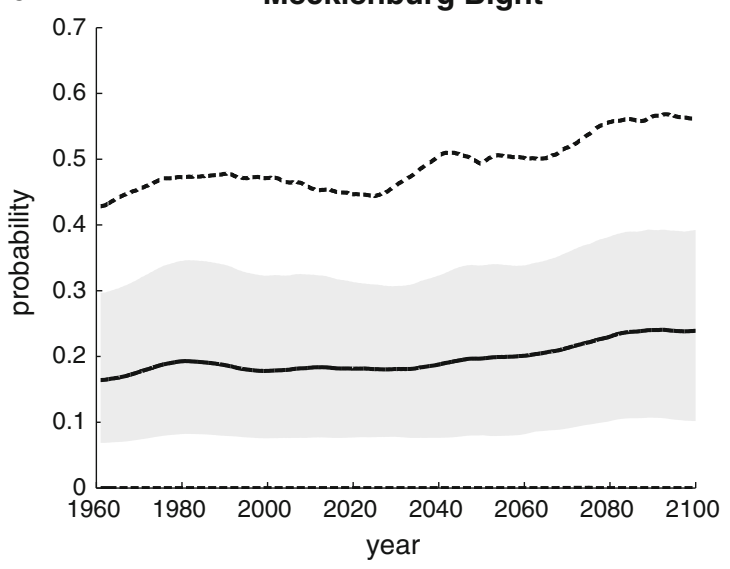

f

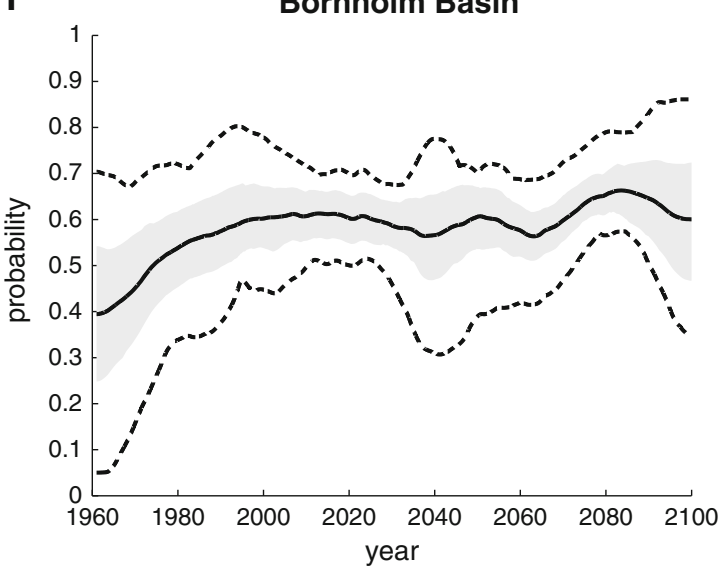

mean and the shaded area shows the $95 \%$ ensemble spread of the mean. The dotted lines are minimum and maximum values in the ensemble. For locations see Fig. 1

reference load scenario, the probability for hypoxic conditions increases at all stations. However, the increase in the Mecklenburg Bight is not as significant as at the other stations. The BSAP nutrient load scenario shows no significant changes. 
For the central Eastern Gotland Sea and the Landsort Deep, the probability of hypoxic conditions is in all cases very high (i.e., close to one) during the entire period 1960-2100 (data not shown). In the BSAP scenario, a tendency for improvement can be seen, however, referring to the ensemble spread, the probability of hypoxia is still high.

The general picture for anoxic conditions looks similar (Fig. S1, Electronic supplementary material). The probability of anoxic conditions increases in the reference nutrient load scenario, while the BSAP load reductions compensate for the climate induced trend. One exception appears in the Eastern Gotland Basin where in the BSAP scenario, the probability of anoxic conditions is reduced after 2020. However, the trend is not significant because of the wide spread of the ensemble mean.

Finally, we studied the duration of hypoxic and anoxic events. Figure 5 shows that the maximum duration of hypoxia approximately doubles in the reference scenario at the end of the century. The duration increases by almost 1 month in the Arkona Basin and by 200 days in the Bornholm Basin. There is also an increasing trend in Mecklenburg Bight but this is not significant. The trend of increasing duration is removed in the BSAP scenario. The maximum duration of anoxic conditions in the reference scenario increases with about 1 week in the Arkona Basin and almost a year in the Bornholm Basin (Fig. S2, Electronic supplementary material). Also in this case, the trend in Mecklenburg Bight is not significant.

\section{Spring Bloom}

In temperate latitudes, primary production usually starts after winter with a strong bloom. The onset of the bloom occurs when light is not limiting in the surface water. This is mostly connected with a thermal stratification, triggered by solar radiation. Our hypothesis was that in a warmer climate, thermal stratification occurs earlier in the spring season and therefore the bloom starts earlier as well. From an analysis of the ensemble simulation we have to reject this hypothesis (see Electronic supplementary material).

\section{Cyanobacteria Blooms}

Above we showed an increasing probability for high SST in a future climate. Consequently, there is a certain risk that cyanobacteria blooms will appear earlier in summer. In the reference scenario, the first occurrence of cyanobacteria blooms in summer is 10 days earlier at the Landsort Deep and 20 days earlier in the Bornholm Basin and the Eastern Gotland Sea (Fig. 6). The results are similar for the BSAP scenario, which shows that nutrient load reductions do not change this pattern.
Salinity

Salinity has a strong impact on the physiology and therefore the distribution of many organisms in the Baltic Sea. Owing to the large salinity range in the Baltic Sea, organisms are adapted to changing salinity. However, a trend or shift in salinity may change the distribution patterns of species. To complement the variables discussed above, we show the salinity response to climate change. In contrast to the other variables, not the extremes but the trends in salinity are in focus.

All models show a clear and significant trend towards lower salinity both in surface (not shown) and bottom water (Fig. 7). An exception is Mecklenburg Bight without a significant change in bottom water salinity, while the surface salinity trend is comparable to the other regions. The salinity decrease is in the order of 2-2.5 PSU at the end of the century in the central Baltic Sea. The reason for the expected decreasing salinity is the projected increasing freshwater supply to the Baltic Sea (Meier and Kauker 2003).

\section{DISCUSSION}

In this study, a multi-model ensemble of climate change projections for the Baltic Sea ecosystem was used to analyze changes in extreme conditions and their statistical properties. The ensemble spread was used to specify the significance of the observed changes.

The probability for high SST in summer increased about two- to three-fold. This may contribute to a prolongation of the touristic season but bears also ecological risks. Satellite-based observations of cyanobacteria show a clear relationship between SST and cyanobacteria bloom strength (Siegel and Gerth 2008). In recent decades, cyanobacteria blooms were much more reduced in years with low summer SSTs, whereas they were clearly detected at times of sufficiently high summer SSTs. The result of our study indicates 20-40 summer days promoting cyanobacteria blooms. At the end of the century, 50-70 summer days will reach sufficient high summer SST, and first cyanobacteria blooms occur 10-20 days earlier. These findings are qualitatively in accordance with Meier et al. (2011a) who found a slight increase in cyanobacteria biomass at the end of the century. However, Neumann (2010) did not find an increase of nitrogen fixation in future scenarios, but detected an earlier appearance of cyanobacteria. The increased potential for cyanobacteria blooms may counteract a benefit of temperature increase for tourism.

Oxygen conditions in general could deteriorate due to climate warming (Meier et al. 2011c), due to decreasing solubility of oxygen in water with increasing temperature, and an acceleration of temperature-dependent degradation 

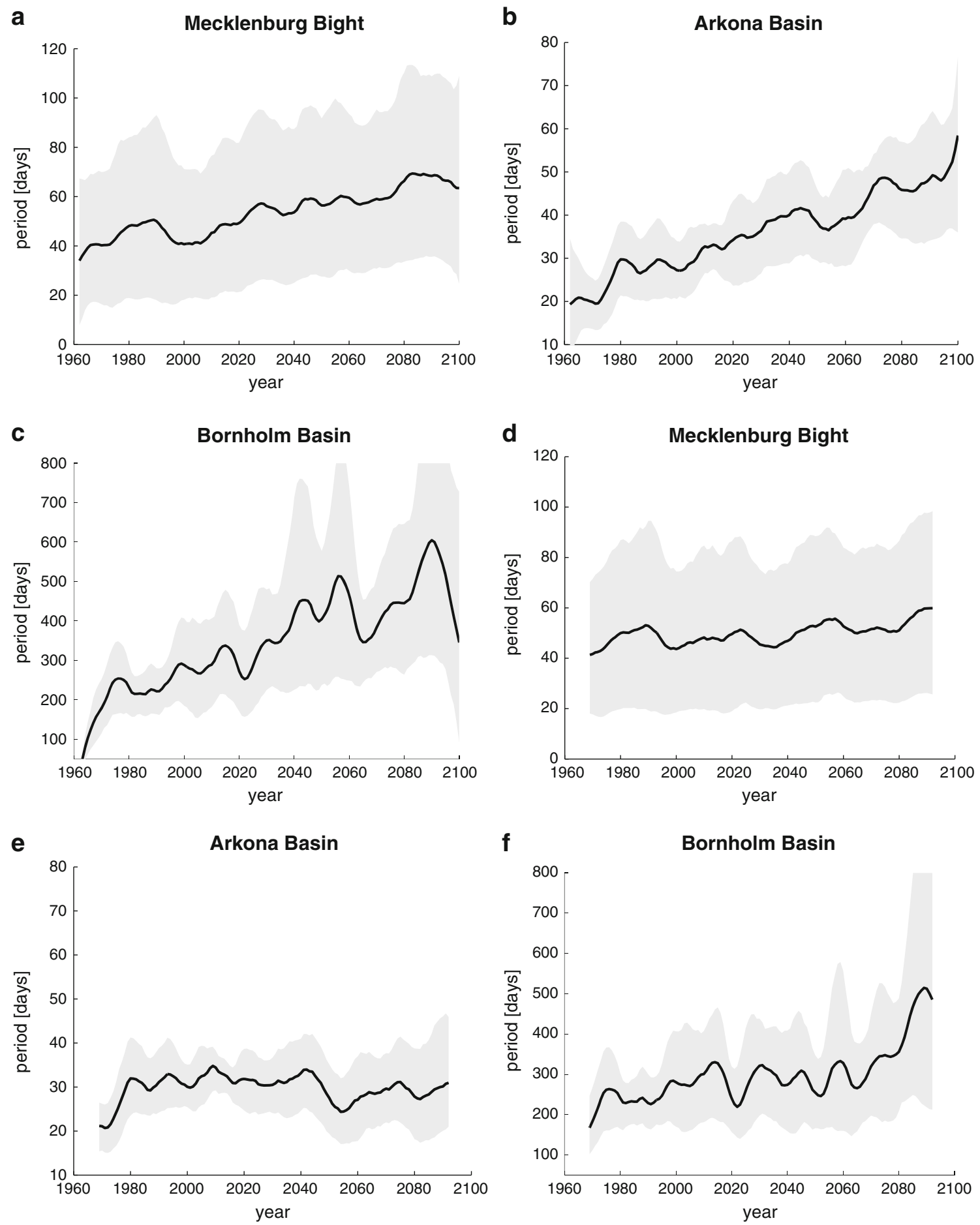

Fig. 5 Maximum duration of hypoxic periods $\left(\mathrm{O}_{2}<2 \mathrm{~mL} \mathrm{~L}^{-1}\right)$. Upper row (a-c) shows results from the reference simulations and the lower row $(\mathbf{d}-\mathbf{f})$ results from the BSAP nutrient load scenario. The

processes (Conley et al. 2009). We found that the probability for hypoxic and anoxic conditions in the future projections increased in most bottom waters of the central Baltic Sea, and the maximum duration of hypoxic and solid line is the ensemble mean and the shaded area shows the $95 \%$ ensemble spread of the mean. For locations see Fig. 1

anoxic events roughly doubled. Anoxia reduces phosphorus sequestration in sediments (Vahtera et al. 2007), and more phosphate may be available in the pelagic system. This could intensify nitrogen fixation. However, model 
a

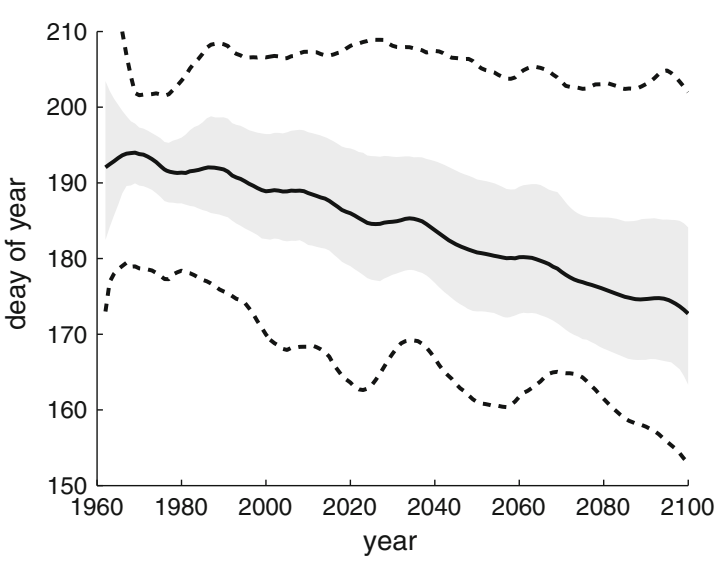

C

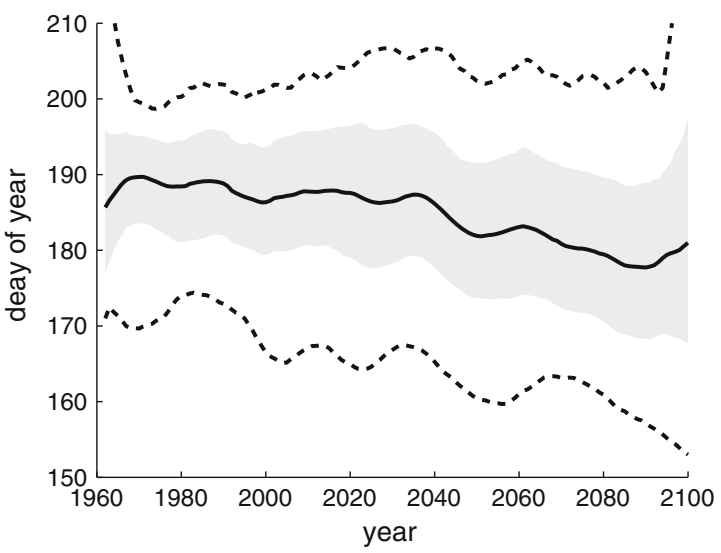

e

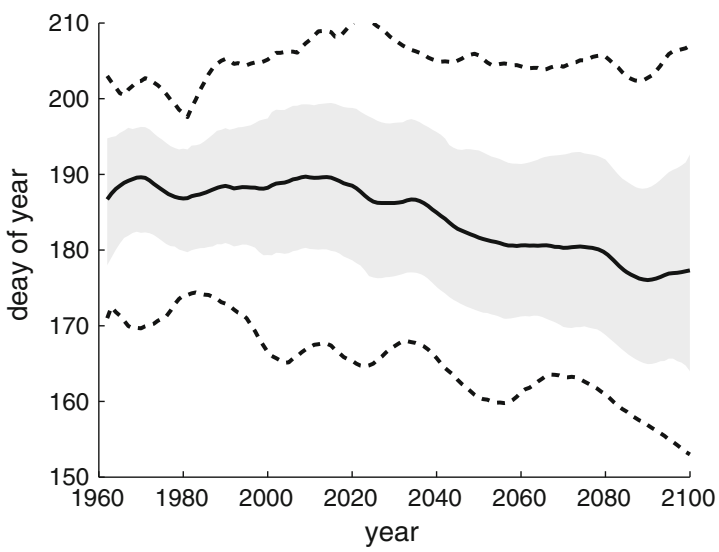

b

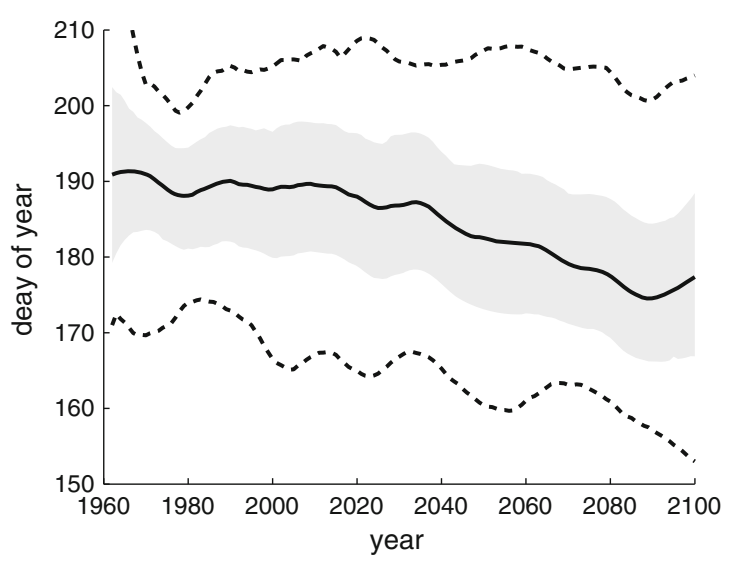

d

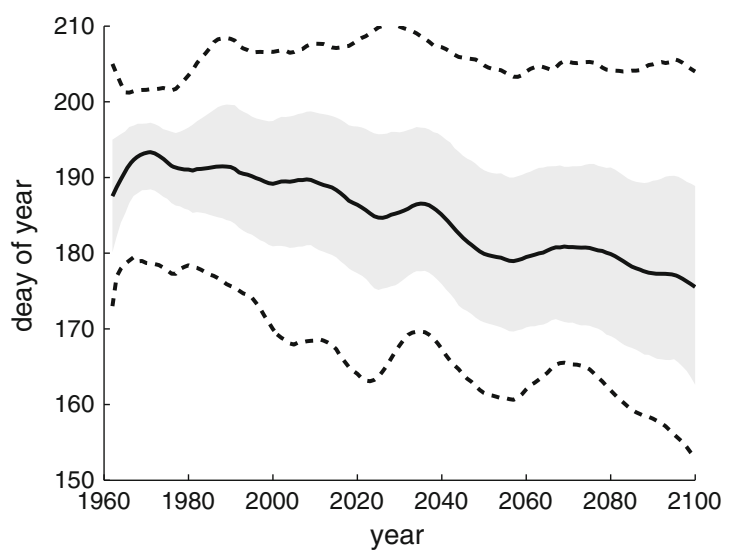

f

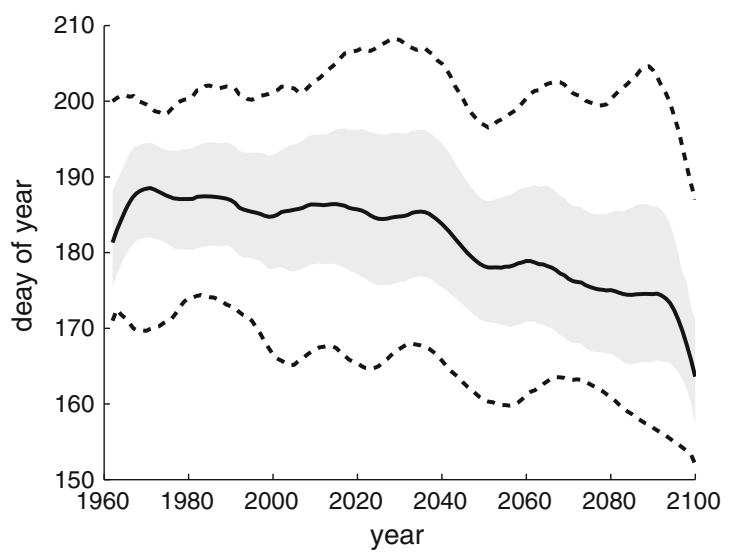

The solid line is the ensemble mean and the shaded area shows the $95 \%$ ensemble spread of the mean. The dotted lines are minimum and maximum values in the ensemble. For locations see Fig. 1

ensemble simulation. The results suggest that environmental targets such as 'natural oxygen level' for the BSAP likely cannot be fixed values. These should instead be considered in the context of the climatic conditions that may change on long time scales. For instance, during the 
a

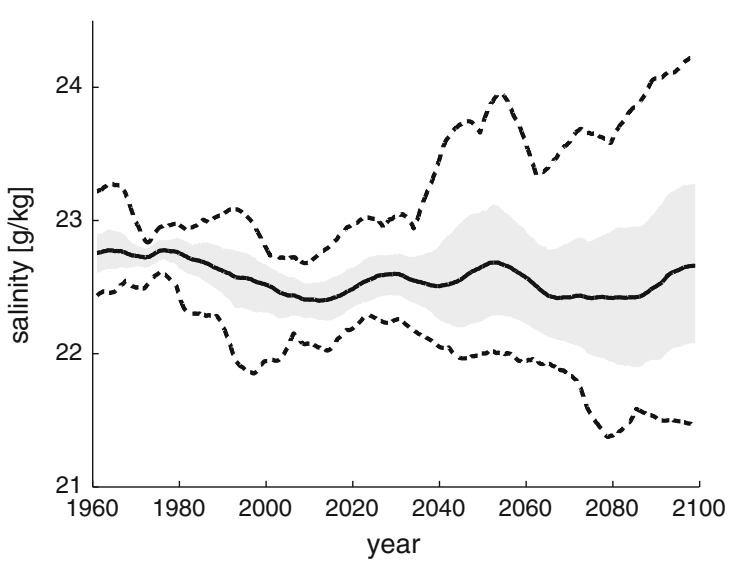

C

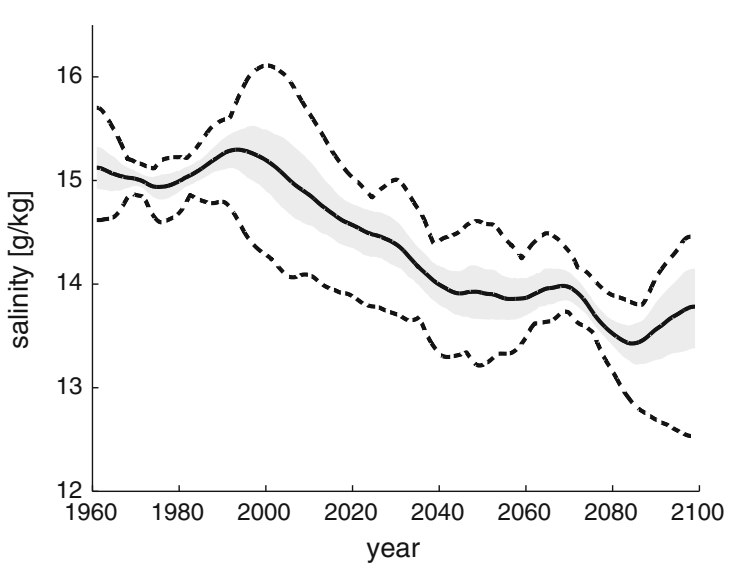

b

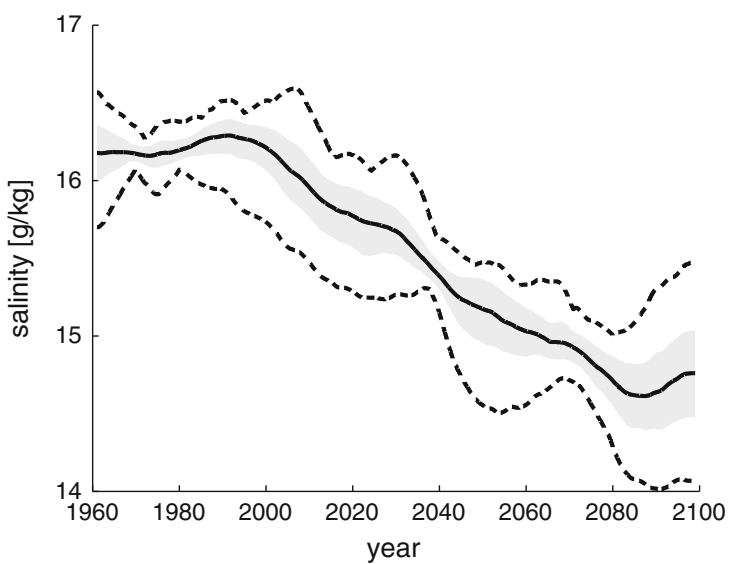

d

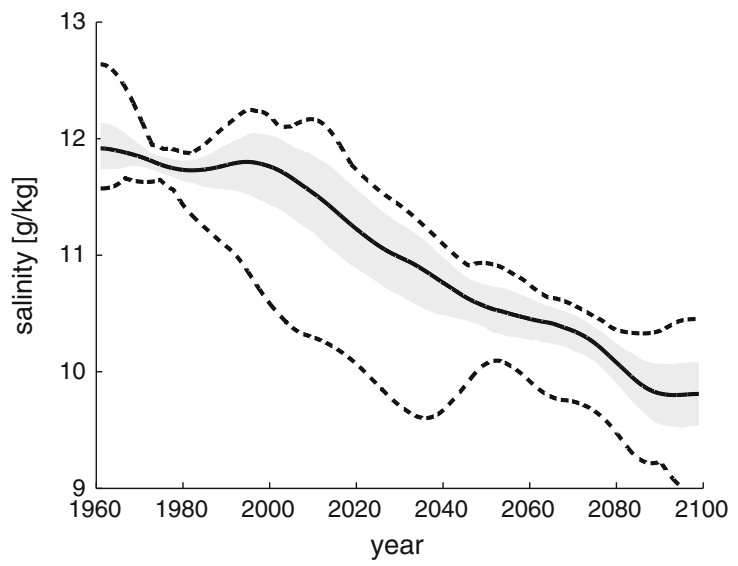

Fig. 7 Deep water salinity at different locations. The solid line is the ensemble mean and the shaded area shows the $95 \%$ ensemble spread of the mean. The dotted lines are minimum and maximum values in the ensemble. For locations see Fig. 1

warm Medieval Climate Anomaly, with most likely lower nutrient loads than today, hypoxic conditions were a common feature in the Baltic Sea (Zillén et al. 2008).

In this study we did not find an earlier spring bloom. The reason for this might be the combination of increased temperature and wind in both the ECHAM-CLM (Neumann 2010) and HadCM3-RCAO (Meier et al. 2011b) combinations. Sensitivity studies by Meier et al. (2011a) showed that temperature increase causes an earlier spring bloom and stronger wind delays the spring bloom.

Salinity shows a clear decreasing tendency in accordance with Meier (2006), Neumann (2010), and Meier et al. (2011c). The magnitude of the change should still be considered as relatively uncertain due to the uncertainty of precipitation in GCMs (Meier et al. 2006). Changing salinity will cause physiological stress to organisms and may change the distribution of species. The western part of the Baltic Sea is less affected by the salinity trend, especially in the bottom water. Here, the surface water is influenced by the outflowing brackish water from the Baltic Sea. The bottom water, however, is formed by inflowing saline water from the open boundaries in the Skagerrak/ North Sea, where the climatology is fixed in the models.

The results related to increased temperatures and decreased salinity correspond well to Meier et al. (2011a) who studied a 40-member ensemble, but included only one ecosystem model and one RCM. The increased hypoxia in the warmer future climate was indicated also in the results by Meier et al. (2011c). Owing to the considerable uncertainty in some projected variables, the development of distinct storylines for the Baltic Sea region might get more robust results. Future studies should also extend the number of climate scenarios in combination with improved catchment scenarios as well. 
Acknowledgments This study is a contribution to the ECOSUPPORT project ("Advanced modeling tool for scenarios of the Baltic Sea ECOsystem to SUPPORT decision making") that has received funding from the European Community's Seventh Framework Programme (FP/2007-2013) under grant agreement 217246 made with the joint Baltic Sea research and development programme BONUS, and from the German Federal Ministry of Education and Research under grant agreement 03F0492A. Supercomputing power was provided by HLRN (North-German Supercomputing Alliance) and from the Swedish Environmental Protection Agency (SEPA, ref. no. 08/381). The RCO-SCOBI model simulations were partly performed on the climate computing resources 'Ekman' and 'Vagn' that are operated by the National Supercomputer Centre (NSC) at Linköping University and the Centre for High Performance Computing (PDC) at the Royal Institute of Technology in Stockholm, respectively. These computing resources are funded by a grant from the Knut and Alice Wallenberg Foundation.

\section{REFERENCES}

BACC Author Team. 2008. Assessment of Climate Change for the Baltic Sea Basin. Springer: Regional Climate Studies.

CLM Community. 2011. Climate limited-area modelling community. http://www.clm-community.eu/. Retrieved October 2011.

Conley, D.J., J. Carstensen, R. Vaquer-Sunyer, and C.M. Duarte. 2009. Ecosystem thresholds with hypoxia. Hydrobiologia 629: 21-29.

Diaz, R.J., and R. Rosenberg. 2008. Spreading dead zones and consequences for marine ecosystems. Science 321: 926-929.

Döscher, R., U. Willén, C. Jones, A. Rutgersson, H.E.M. Meier, U. Hansson, and L.P. Graham. 2002. The development of the regional coupled ocean-atmosphere model RCAO. Boreal Environment Research 7: 183-192.

Eilola, K., B.G. Gustafson, I. Kuznetsov, H.E.M. Meier, T. Neumann, and O.P. Savchuk. 2011. Comparison of observed and simulated dynamics of biogeochemical cycles in the Baltic Sea during 1970-2005 using three state-of-the-art numerical models. Journal of Marine Systems 88: 267-284.

Eilola, K., H.E.M. Meier, and E. Almroth. 2009. On the dynamics of oxygen, phosphorus and cyanobacteria in the baltic sea: A model study. Journal of Marine Systems 75: 163-184.

Elmgren, R. 2001. Understanding human impact on the Baltic ecosystem: Changing views in recent decades. AMBIO 30: 222-231.

Feistel, R., G. Nausch, and N. Wasmund (eds.). 2008. State and evolution of the Baltic Sea, 1952-2005: A detailed 50-year survey of meteorology and climate, physics, chemistry, biology, and marine environment. Hoboken: Wiley.

Finni, T., K. Kononen, R. Olsonen, and K. Wallström. 2001. The history of cyanobacterial blooms in the Baltic Sea. AMBIO 30: 172-178.

Gordon, C., C. Cooper, C.A. Senior, H. Banks, J.M. Gregory, T.C. Johns, J.F.B. Mitchell, and R.A. Wood. 2000. The simulation of SST, sea ice extents and ocean heat transports in a version of the Hadley Centre coupled model without flux adjustments. Climate Dynamics 16: 147-168.

HELCOM. 2011. HELCOM Baltic Sea Action Plan. http://www.helcom. fi/BSAP/ActionPlan/en_GB/ActionPlan/. Retrieved October 2011.

Hollweg, H.-D., U. Böhm, I. Fast, B. Hennemuth, K. Keuler, E. KeupThiel, M. Lautenschlager, S. Legutke, et al. 2008. Ensemble simulations over Europe with the regional climate model CLM forced with IPCC AR4 global scenarios. http://www.mad.zmaw.de/
fileadmin/extern/SGA-Files/CLM_report_readme/CLM_technical_ report_2009-07-21.pdf. Retrieved October 2011.

IPCC. 2007. Climate Change 2007. Synthesis Report. http://www.ipcc. ch/publications_and_data/ar4/syr/en/contents.html. Retrieved March 2012.

IPCC. 2009. Intergovernmental Panel on Climate Change. from http://www.ipcc.ch/. Retrieved October 2011.

Jiguet, F., L. Brotons, and V. Devictor. 2011. Community responses to extreme climatic events. Current Zoology 57: 406-413.

Kanoshina, I., U. Lips, and J.M. Leppanen. 2003. The influence of weather conditions (temperature and Wind) on Cyanobacterial bloom development in the Gulf of Finland (Baltic Sea). Harmful Algae 2: 29-41.

Lips, I., and U. Lips. 2008. Abiotic factors influencing cyanobacterial bloom development in the Gulf of Finland (Baltic Sea). Hydrobiologia 614: 133-140. doi:10.1007/s10750-008-9449-2.

Meier, H.E.M. 2006. Baltic Sea climate in the late twenty-first century: A dynamical downscaling approach using two global models and two emission scenarios. Climate Dynamics 27: 39-68.

Meier, H.E.M., and F. Kauker. 2003. Modeling decadal variability of the Baltic Sea: 2. Role of freshwater inflow and large-scale atmospheric circulation for salinity. Journal of Geophysical Research 108: 3368.

Meier, H.E.M., E. Kjellström, and L.P. Graham. 2006. Estimating uncertainties of projected Baltic Sea salinity in the late 21st century. Geophysical Research Letters 33: L15705. doi:10.1029/ 2006 GL026488.

Meier, H.E.M., K. Eilola, and E. Almroth. 2011a. Climate-related changes in marine ecosystems simulated with a 3-dimensional coupled physical-biogeochemical model of the Baltic Sea. Climate Research 48: 31-55.

Meier, H.E.M., A. Höglund, R. Döscher, H. Andersson, U. Löptien, and E. Kjellström. 2011b. Quality assessment of atmospheric surface fields over the baltic sea from an ensemble of regional climate model simulations with respect to ocean dynamics. Oceanologia 53: 193-227.

Meier, H.E.M., H.C. Andersson, K. Eilola, B.G. Gustafsson, I. Kuznetsov, B. Müller-Karulis, T. Neumann, and O.P. Savchuk. 2011c. Hypoxia in future climates-A model ensemble study for the Baltic Sea. Geophysical Research Letters 38: L24608. doi: 10.1029/2011GL049929.

Meier, H.E.M., B. Müller-Karulis, H.C. Andersson, C. Dietrich, K. Eilola, B.G. Gustafsson, A. Höglund, R. Hordoir, et al. 2012. Impact of climate change on ecological quality indicators and biogeochemical fluxes in the Baltic Sea-A multi-model ensemble study. AMBIO. doi:10.1007/s13280-012-0320-3

Neumann, T. 2010. Climate-change effects on the Baltic Sea ecosystem: A model study. Journal of Marine Systems 81: 213-224.

Neumann, T., and G. Schernewski. 2008. Eutrophication in the Baltic Sea and shifts in nitrogen fixation analyzed with a 3D ecosystem model. Journal of Marine Systems 74: 592-602.

Roeckner, E., R. Brokopf, M. Esch, M. Giorgetta, S. Hagemann, L. Kornblueh, E. Manzini, U. Schlese, et al. 2006. Sensitivity of simulated climate to horizontal and vertical resolution in the ECHAM5 atmosphere model. Journal of Climate 19: 3771-3791.

Savchuk, O.P. 2002. Nutrient biogeochemical cycles in the Gulf of Riga: Scaling up field studies with a mathematical model. Journal of Marine Systems 32: 235-280.

Siegel, H., and M. Gerth. 2008. Optical remote sensing applications in the enclosed Baltic Sea. In Remote sensing of European Seas, ed. Barale, V., and M. Gade, 91-102. Berlin: Springer.

Vahtera, E., D.J. Conley, B.G. Gustafsson, H. Kuosa, H. Pitkänen, O.P. Savchuk, T. Tamminen, M. Viitasalo, et al. 2007. Internal ecosystem feedbacks enhance nitrogen-fixing cyanobacteria blooms and complicate management in the Baltic Sea.AMBIO 36: 186-194. 
Walther, G.-R., E. Post, P. Convey, A. Menzel, C. Parmesan, T.J.C. Beebee, J.-M. Fromentin, O. Hoegh-Guldberg, et al. 2002. Ecological responses to recent climate change. Nature 416: 389-395.

Wasmund, N. 1997. Occurrence of cyanobacterial blooms in the baltic sea in relation to environmental conditions. Internationale Revue der Gesamten Hydrobiologie 82: 169-184.

Wasmund, N., G. Nausch, B. Schneider, K. Nagel, and M. Voss. 2005. Comparison of nitrogen fixation rates determined with different methods: A study in the Baltic Proper. Marine Ecology Progress Series 297: 23-31.

Zillén, L., D.J. Conley, T. Andrén, E. Andrén, and S. Björck. 2008. Past occurrences of hypoxia in the Baltic Sea and the role of climate variability, environmental change and human impact. Earth-Science Reviews 91: 77-92.

\section{AUTHOR BIOGRAPHIES}

Thomas Neumann $(\varangle)$ is a senior scientist working in the department of Physical Oceanography in the Baltic Sea Research Institute (IOW). After an initial oceanographic career in small-scale processes in the sea he turned his scientific interest in the 1990s to coupled physical and biogeochemical modeling.

Address: Leibniz-Institute for Baltic Sea Research Warnemünde, Seestr. 15, 18119 Rostock, Germany.

e-mail: Thomas.Neumann@io-warnemuende.de

Kari Eilola is an oceanographer and senior scientist at the department of Research and Development at the Swedish Meteorological and Hydrological Institute (SMHI). His research interests include physical and biogeochemical modeling of the Baltic Sea.

Address: Swedish Meteorological and Hydrological Institute, Sven Källfelts gata 15, 42671 V Frölunda, Sweden.

e-mail: kari.eilola@smhi.se

Bo Gustafsson is associate professor in Physical Oceanography and presently works as managing director of the Baltic Nest Institute, Stockholm University. The main research focus being modeling of the Baltic Sea region, in particular problems related to eutrophication. Address: Baltic Nest Institute, Stockholm University, 10691 Stockholm, Sweden.

e-mail: bo.gustafsson@stockholmresilience.su.se
Bärbel Müller-Karulis is a guest researcher at the Baltic Nest Institute, Stockholm University. She has worked with Baltic ecosystem status assessment and biogeochemical modeling at the Latvian Institute of Aquatic Ecology since 1997. In 2010 she earned a PhD from the University of Latvia with focus on biogeochemical modeling.

Address: Baltic Nest Institute, Stockholm University, 10691 Stockholm, Sweden.

e-mail: Baerbel.muller-karulis@stockholmresilience.su.se

Ivan Kuznetsov is working at the Oceanographic Research group at the Swedish Meteorological and Hydrological Institute (SMHI). His research interests include numerical modeling of the Baltic Sea ecosystem.

Address: Swedish Meteorological and Hydrological Institute, Folkborgsvägen 1, 60176 Norrköping, Sweden.

e-mail: ivan.kuznetsov@smhi.se

H. E. Markus Meier is adjunct professor at Stockholm University and head of the Oceanographic Research Unit at the Swedish Meteorological and Hydrological Institute (SMHI). His current research interests focus on the analysis of climate variability and the impact of climate change on the physics and biogeochemical cycles in the Baltic Sea, North Sea and Arctic Ocean.

Address: Swedish Meteorological and Hydrological Institute, Folkborgsvägen 1, 60176 Norrköping, Sweden.

e-mail:markus.meier@smhi.se

Oleg P. Savchuk graduated from the Leningrad State University (USSR) in 1971 as oceanographer. Since then he uses mathematical modeling as a tool to study marine ecosystems of the Baltic, White, and Barentz seas with emphasis on nutrient biogeochemical cycles. Address: Baltic Nest Institute, Stockholm University, 10691 Stockholm, Sweden.

e-mail: oleg@mbox.su.se 